\title{
D

\section{Economia e instituições importam? Um estudo do comportamento eleitoral em países latino-americanos}

\author{
Economy and institutions matter? A study of electoral behavior in \\ latin american countries
}

\section{Jaqueline da Silva Borges}

\section{Resumo}

Os estudos de comportamentos eleitorais contemporâneos, para além de entender a relevância de aspectos econômicos, têm incorporado em suas análises as variáveis de caráter institucional. De acordo com esse aporte teórico, é preciso atentar para o contexto político em que os eleitores estáo inseridos. Partindo de tais preceitos, o presente trabalho tem por objetivo analisar a relevância de aspectos econômicos e institucionais no comportamento eleitoral de dezoito países latino-americanos entre 2008 e 2012. Assim, mensura-se em que medida as variáveis institucionais se mostram relevantes no vínculo que o eleitor estabelece entre desempenho de governo na economia e a avaliação dada ao governante. Os principais achados reforçam, em parte, a pertinência de variáveis institucionais no voto econômico.

\section{Palavras-chave}

Comportamento Eleitoral; Instituiçóes; Voto Econômico.

\begin{abstract}
Studies of contemporary electoral behavior, in addition to understand the relevance of economic, have incorporated in their analysis variables of the institutional character. According to this theoretical framework, it is necessary to consider the political context in which voters are in. Starting from such precepts, this study aims to analyze the relevance of economic and institutional aspects in the electoral behavior of eighteen Latin American countries between 2008 and 2012. Thus, it measures in the extent to which institutional variables are relevant in the connection established by the voter between the performance of government in the economy and the rate given to the ruler. The main findings reinforce, in part, the relevance of institutional variables in the economic vote.
\end{abstract}

\section{Keywords}

Electoral Behavior; Institutions; Economic Vote. 


\section{Introdução}

Países latino-americanos apresentam peculiaridades históricas e institucionais que precisam ser contempladas quando pretende-se traçar uma análise sobre o processo de consolidação democrática. Para além das rupturas e transições democráticas que se deram de modos distintos, o desenho institucional do presidencialismo também apresenta diferenciaçôes pertinentes. Assim, em um contexto em que a literatura reforça o voto econômico e há a presença de crise econômica e política, faz-se importante a inserção de variáveis institucionais em estudos sobre comportamento eleitoral.

Esse enfoque entende que o indivíduo não faz suas escolhas em um ambiente neutro. Assim, além de analisar as preferências de um indivíduo, para uma maior compreensáo do comportamento eleitoral faz-se importante também mensurar as opçôes que se tornam disponíveis no contexto em que o indivíduo está inserido. A clareza de responsabilidade, conceito da ciência política relacionado ao ambiente de formulação de políticas e à capacidade do eleitor de discernir a produçáo efetiva do governo, para puni-lo ou recompensá-lo, contempla a apreensão contemporânea de estudos de comportamento eleitoral e será um dos conceitos chave deste trabalho.

Atentando especificamente para o desenho institucional de países presidencialistas, Shugart e Carey (1992) também contribuem para essa discussão com o modelo teórico acerca da eficiência de sistema. Um sistema eficiente, segundo Shugart e Carey (1992), na mesma linha do conceito de clareza de responsabilidade, seria aquele relacionado com uma capacidade elevada de identificaçáo e diferenciação das informaçôes a disposição do eleitor. Tal discernimento dos programas políticos dispostos ao eleitor é de suma importância não só por interferir na avaliação de governo, como também faria diferença na decisão eleitoral.

Assim, tendo por base tal discussão teórica, o presente trabalho tem por objetivo geral analisar o comportamento eleitoral do latino-americano. Mais especificamente, analisar a relevância de aspectos econômicos e institucionais nas avaliaçôes de governos de dezoito países latino-americanos entre os anos 2008 e 2012. Tendo como variável dependente a avaliação de governo, mensura-se em que medida as variáveis institucionais se mostram relevantes no vínculo que o eleitor estabelece entre desempenho de governo na economia e a avaliação dada ao governante. Para o alcance desses objetivos, foram utilizados bancos de dados fornecidos pelo Barômetro das Américas, bem como informaçóes coletadas do CEPAL, PNUD, Banco Mundial, Georgetown University e sites governamentais. 
O trabalho está estruturado do seguinte modo: além desta introdução, será feito um breve panorama da produção científica do voto econômico. Acompanhando os desdobramentos da literatura, será incorporada a essa discussão do voto econômico a discussão institucionalista com o conceito de clareza de responsabilidade e sistema eficiente. A seção seguinte contempla análises, que buscam averiguar como as variáveis institucionais alteram a relação entre avaliação econômica e avaliação presidencial. Por fim, nas consideraçôes finais, pretende-se retomar os principais achados deste trabalho, bem como apontar direcionamentos futuros possíveis.

\section{Economia como variável explicativa do comportamento eleitoral}

Com diferenças no que se referem às variáveis empregadas, bem como o nível de análise, muitos são os estudos contemporâneos que reforçam a tese do voto econômico. Tais estudos, inicialmente, centravam-se em regióes ou países mais desenvolvidos, como é o caso da Europa Ocidental e Estados Unidos. Essas pesquisas tinham por enfoque as implicaçóes eleitorais decorrentes do desempenho do mandatário no campo econômico, como o "political business cycle" ou a força relativa de questôes econômicas na decisão eleitoral (BECK, 1982; BELLUCCI, 1984; EULAU e LEWIS-BECK, 1985; FRANZ, 1986; HIBBS e FASSBENDER, 1981; LEWIS-BECK, 1988; TUFTE, 1978; VISSER e WIJNHOVEN, 1990 apud REMMER, 1991). Os estudos latino-americanos, inseridos nesse debate econômico, por sua vez, colocariam em um segundo plano as questóes eleitorais. Isso decorre por haver maior enfoque em análises de relação entre as condiçóes econômicas e rupturas democráticas, que limitavam, inclusive, o número de pleitos realizados (REMMER, 1991; WEYLAND, 1998).

Tais estudos sobre voto econômico poderiam, de acordo com Lewis-Beck e Stegmaier (2000), ser divididos em três ondas. Embasados em análise de nível agregado, contemplando estudos transnacionais ou séries temporais, a primeira onda trabalharia essencialmente com dados econômicos macroestruturais, tais como taxa de desemprego, Produto Interno Bruto (PIB), renda e inflação. A segunda onda de estudos, por sua vez, faz uso de variáveis subjetivas de análise do desempenho econômico. Além disso, há a incorporação de avaliação retrospectiva e prospectiva. Por fim, a terceira onda de estudos sobre comportamento eleitoral incorpora em seus modelos analíticos variáveis de caráter contextual. Esta última onda problematiza o 
modo como desenhos institucionais podem impactar na relação estabelecida entre avaliação econômica e avaliação de governo.

Além dessas três ondas, os estudos sobre o voto econômico em democracias avançadas diferenciam-se também quanto a variável dependente empregada. O resultado eleitoral tem sido a variável comumente utilizada. Entretanto, Lewis-Back e Steigmaier (2008) apontam que a avaliação de governo é uma variável também válida para mensuração do comportamento eleitoral. Assim, os autores pontuam essa lacuna em estudos transnacionais na América Latina.

Em relação às variáveis independentes, Lewis-Back e Steigmaier (2008) pontuam a ausência de uma padronização e isto poderia ser justificado pela datação recente de estudos eleitorais. Remmer (1991) aponta que a inflação e crescimento econômico seriam índices macroeconômicos tradicionalmente aceitos na literatura. $\mathrm{Na}$ América Latina, a taxa de câmbio torna-se uma dimensão internacional relevante para apreensáo de crise na regiáo. Como o autor pontua, tanto os indicadores de inflação, quanto de câmbio, por serem disponibilizados a cada trimestre, tornam possível o acompanhamento do impacto da economia na apreensão do comportamento eleitoral ao longo de um determinado tempo.

Weyland (2000) sugere que os índices econômicos que se mostram relevantes no seio da sociedade mudariam de acordo com o contexto. Em momentos de crise, os eleitores focariam em determinadas pautas econômicas, mas, depois de sanadas, haveria uma espécie de migração para outro aspecto econômico. Weyland (2000) pontua ainda que os louros de resolução de uma crise não se revertem em uma gratidão duradoura ao mandatário.

Singer (2013) segue a mesma linha de argumentação de Weyland (2000). Singer (2013) tem como pressuposto geral que a crise inflacionária, que caracterizou o cenário econômico da década de 80 na América Latina e que era um tema central nos processos eleitorais, perde sua força entre 2000 e 2010. Ou seja, uma vez estabilizado os índices inflacionários, já não seria possível observar um impacto nas decisóes eleitorais. Tendo por base dados individuais a nível agregado, o autor confirma também que a proporção de latino-americanos que apontam que a inflação está entre os problemas de maior relevância decresce com o passar dos anos.

Assim, mais importante do que verificar o impacto da economia no comportamento eleitoral, para Singer (2013), é verificar quais índices se mostram mais relevantes de acordo com o contexto em que estão inseridos os países em análise. Mas de todo modo, questôes econômicas apresentam-se sempre como relevantes nas discussóes eleitorais na medida em que os eleitores se preocupam com interesses 
materiais. Singer (2013) também pontua que demandas econômicas tendem a ocupar mais espaço na agenda pública em países vulneráveis, economicamente falando.

A divergência entre a percepçáo do eleitor a respeito da economia e o real desempenho da economia é outra questão que aparece quando temos por apreensão o voto econômico. Intentando analisar como seria a percepçáo dos eleitores a respeito da economia, Lewis-Beck, Martini e Kiewiet (2013) fazem uso de dados do Estudo Nacional de Eleiçôes Americanas (ANES), entre 1968 e 2008. A suposição acerca da incoerência que poderia estar presente no sistema de crenças das massas não se sustenta: as percepçóes a respeito do desenvolvimento da economia coincidem com o desempenho real da economia. Assim, tal estudo, a respeito do voto retrospectivo econômico, embasado em aspectos subjetivos, apresenta indícios de uma base segura para empreender o impacto da economia em processos eleitorais.

Os estudos sobre voto econômico, de um modo geral, confirmam que, apesar da carência analítica que sofriam países latino-americanos, o desempenho do candidato situacionista na esfera econômica é levado em consideração durante processos eleitorais (REMMER, 1991; WEYLAND, 1998; BENTON, 2003; LEWIS-BECK e RATO, 2013; VEIGA, 2013). Os estudos também apontam que não há definiçóes muito rígidas acerca do impacto de uma avaliação prospectiva ou retrospectiva, bem como se esta é egoísta ou sociotrópica. Em relação a qual área da economia é, de fato, relevante, é possível averiguar que essas estariam suscetíveis ao cenário econômico e social do país em análise. $\mathrm{O}$ desenho institucional também se apresenta como um aspecto pertinente nos estudos de voto econômico, como será pontuado na próxima seção.

\section{Comportamento eleitoral pela perspectiva neoinstitucionalista}

Em paralelo à emergência de questóes neoinstitucionalistas na ciência política, houve a expansão de diversos projetos que visavam a formaçáo de bancos de dados transnacionais (ANDERSON, 2007). Essa expansão foi acompanhada de um crescente número de democracias que se tornariam passíveis de serem estudadas, bem como o desenvolvimento tecnológico e avanço em técnicas estatísticas que permitiriam desenvolver a análise comparativa entre países, como também, a aplicação de modelos hierárquicos. Assim, estudos de comportamento eleitoral pelo viés institucionalista tornaram-se possível.

Sniderman e Levenduscky (2007) apontam que, partindo do pressuposto que o contexto institucional impacta na decisão eleitoral, tem-se a necessidade de analisar 
tal processo tendo em vista uma dimensão interna e externa. $\mathrm{O}$ aspecto interno versa sobre a captaçáo de preferência do eleitor tendo em vista as opçóes que se tornam disponíveis em um determinado contexto. Já em relação à dimensão externa, segundo os autores, é necessário empreender uma análise a respeito da natureza das escolhas que se tornam disponíveis. Reforçando tal ponto de vista, Anderson (2007) afirma que:

As pessoas não vivem em um vácuo. Eles formam atitudes e fazem escolhas em ambientes variáveis, que vem na forma de regras formais institucionais que governam o comportamento das pessoas ou na forma de diferentes condiçóes econômicas, sociais e políticas, que moldam a interpretação e a forma de ação das pessoas (ANDERSON, 2007, p. 590).

Haveria, segundo Dalton e Anderson (2011), três modos em que é possível observar o papel do contexto político nas escolhas eleitorais: diretamente, indiretamente e de forma interveniente. Compreende-se por efeitos de forma direta, por exemplo, a definição de diretrizes institucionais que poderão fazer o eleitor racional se abster do ato de voto, ou de se dirigir às urnas. Enquanto que o de forma indireta, refere-se a uma influência em que se afeta uma variável independente, que por sua vez irá afetar a variável dependente. Um exemplo desse efeito indireto seriam as regras eleitorais que modificam o cálculo e o comportamento dos dirigentes, e, assim, têm-se modificaçōes no "cardápio" disponível para escolha do eleitor. Por fim, compreende a influência de forma interativa quando se têm uma terceira variável na análise em questão. Dentre essas possibilidades de consequências institucionais no comportamento do eleitor, Anderson (2007) salienta que tanto teoricamente, como empiricamente, quando se aprofunda a discussão, os efeitos são mais de caráter secundários ou indiretos, do que direto, propriamente dito.

De acordo com Dalton e Anderson (2011), o contexto político, considerando o sistema eleitoral e político, pode moldar o comportamento político ao determinar "[...] o número de escolhas, a natureza das escolhas, e a previsibilidade das escolhas" (DALTON e ANDERSON, 2011, p. 9). No que se refere ao número de opçóes elegíveis, como apontam Dalton e Anderson (2011), “[...] a diversidade das escolhas é mais relevante que o número" (DALTON e ANDERSON, 2011, p. 10). Como quantidade não necessariamente reflete em diversidade ideológica, cabe também averiguar a natureza das opçóes à disposição. Com tal intuito, uma medida possível é analisar o grau de polarização ideológica. A estabilidade das escolhas é outro ponto 
relevante dentre os aspectos institucionais que se relacionam a escolha eleitoral. Quando se verifica elevada volatilidade eleitoral, existiriam maiores dificuldades para se estabelecer o voto econômico tendo em vista as escolhas programáticas.

Tais concepçôes teóricas são contempladas em algumas discussóes sobre o voto econômico (ANDERSON, 2000; DORUSSEN e TAYLOR, 2001; NORPOTH, 2001; PALDAM, 1991; POWELL e WHITTEN, 1993; RUDOLPH, 2003; SAMUELS, 2004 apud ANDERSON, 2007). Busca-se, nesses trabalhos, averiguar em que medida a avaliação sobre o desempenho econômico do mandatário, que seria revertida em decisão eleitoral, está sujeita a estrutura institucional em que o indivíduo está inserido.

\section{Clareza de responsabilidade}

Powell e Whitten (1993) partem do pressuposto que há quatro aspectos do contexto político que devem ser levados em consideração, já que influenciariam a avaliação realizada pelos indivíduos a respeito do desempenho econômico do mandatário. Inicialmente, os autores pontuam a necessidade de analisar a avaliação do desempenho econômico do país em estudo, com vistas em outras democracias industrializadas, na mesma faixa temporal. Além do saldo de votos do mandatário em eleição anterior, tanto a imagem ideológica do governo quanto a clareza de responsabilidade são aspectos contextuais relevantes para se compreender $\mathrm{o}$ comportamento eleitoral.

Clareza da responsabilidade, que, de acordo com o objetivo do trabalho, terá maior enfoque, está relacionada ao ambiente de formulação de políticas e a capacidade de o eleitor discernir a produção efetiva do governo para puni-lo ou recompensá-lo. Ao ter em vista tal discussão acerca da influência institucional sobre o comportamento do eleitor racional, Powell e Whitten (1993) aludem que

[...] a ligação crítica de atribuição do eleitor de responsabilidade para o governo não é meramente uma idiossincrasia a nível individual ou racionalização. Pelo contrário, refletem fortemente a natureza da formulação de políticas na sociedade e da coerência e controle que o governo pode exercer sobre essa política. Quanto maior o controle percebido unificado de políticas por parte do governo em exercício, mais provável é que o cidadão atribua a responsabilidade por resultados econômicos e políticos ao incumbente (POWELL e WHITTEN, 1993, p. 398). 
Dito de outro modo, a avaliação sobre o desempenho econômico do governante estaria sujeita ao ambiente institucional de formulação de políticas. Essa relação ocorre na medida em que o contexto político tem potencial de alterar o grau de responsabilidade atribuído ao governante pela sociedade.

Dentre os fatores que auxiliariam na clareza de responsabilidade, Powell e Whitten (1993) pontuam a necessidade de uma elevada inserçâo do partido situacionista em comissóes no sistema legislativo. Tal aspecto é relevante na medida em que todos os partidos têm a possibilidade de ocupação das cadeiras de maneira igual, inclusive a oposição. Assim, quando se observa um legislativo muito fragmentado, a oposição pode vir a ter poder também de interferir na formulação política e, por consequência, tende a diminuir a clareza de responsabilidade. Espera-se que em sistemas políticos em que há mais envolvimento da oposição na esfera legislativa, os candidatos situacionistas tendam a perder menos votos (ou ganhar mais votos), uma vez que serão menos penalizados, ou recompensados, em decorrência da baixa clareza de responsabilidade. Assim, quanto maior o número de fragmentação partidária entende-se que menor será o nível de clareza de responsabilidade, uma vez que - supostamente - maior será a dificuldade do partido situacionista em ocupar uma parcela significativa das cadeiras. Em países em que o sistema legislativo é bicameral (Câmara dos Deputados e Senado), é relevante que o partido situacionista ocupe a maioria de assentos em ambas as casas, para elevado índice de clareza de responsabilidade.

Países que detém um elevado número de partidos efetivos necessitam, para que haja governabilidade, recorrer a mecanismos tais como a coalizão. Tal recurso, dentro do aporte teórico sobre clareza de responsabilidade, todavia, é observado como um aspecto que tende a diminuir a capacidade de discernimento a respeito dos responsáveis das políticas implementadas.

Outro aspecto que pode vir a incidir sobre a clareza de responsabilidade de uma determinada gestão, tendo em vista o processo em que se dá a relação entre executivo e legislativo, seria a ausência de coesão em votaçóes do partido que compóe o governo. O partido, que seria "[...] o grande unificador para o eleitor na urna" (POWELL e WHITTEN, 1993, p. 399), ao não votar de forma coesa, disponibilizaria meios para que a oposição interferisse na formulação de políticas. A capacidade de agendamento legislativo do partido situacionista e de sua coalizão depende de lealdade e disciplina partidária dos componentes da base governista. Em um cenário em que não se tenha lealdade e disciplina partidária, a relação executivolegislativo é imprevisível, embora isso possa ser visto como positivo na medida em 
que o presidente pode vir a negociar (MAINWARING, 2002). Quando o comportamento da base governista no legislativo tende a ser coeso, pressupóe-se que a elaboração e a implementação de políticas ganharão contornos específicos, sendo esses discerníveis para o eleitor e, assim, elevando a clareza de responsabilidade. Por isso, além de ocupar uma maioria parlamentar, é importante verificar se há disciplina partidária.

Aspectos institucionais que interferem no que se está entendendo por clareza de responsabilidade estão inter-relacionados. Como aponta Powell e Witten (1993), um sistema eleitoral e partidário que não assegura clareza às açôes dos partidos situacionistas, é normalmente aquele com legislativo com representação proporcional, que, por sua vez, eleva a fragmentação partidária e terá, assim, maiores chances de formar um governo minoritário.

Partindo de tais concepçóes teóricas, Powell e Whitten (1993) analisaram dezenove países, separando entre aqueles que possuem as características que auxiliam na clareza da responsabilidade daqueles que não possuem. Nos oito casos que se enquadraram com baixos índices de clareza de responsabilidade, os efeitos econômicos tenderam a explicar pouco o voto no candidato situacionista, ao passo que nos demais onze países, o impacto do desempenho econômico sobre a escolha eleitoral é relativamente mais forte. Cabe salientar, todavia, que os autores náo desmerecem a relevância do desempenho econômico em qualquer democracia.

Compreendendo que há diversas formas possíveis de problematizar o contexto político a fim de averiguar o impacto da avaliação econômica na decisão eleitoral, Anderson (2000) entende que a clareza de responsabilidade seria o aporte teórico mais adequado para tal objetivo, uma vez que parte do pressuposto que o eleitor é um agente racional, prezando pela redução dos gastos e maximização de benefícios em suas escolhas. Cenários com maior clareza de responsabilidade política poderiam refletir em uma punição ou recompensa mais ostensiva do que em cenários com responsabilidades nebulosas. Assim, o autor, incorporando ao conceito questóes como clareza das alternativas disponíveis, bem como, o tamanho do partido situacionista, analisa treze democracias europeias.

A incorporação do aspecto que versa sobre clareza de alternativas disponíveis é justificada pelo autor na medida em que a clareza de responsabilidade só faz sentido quando se tem alternativas viáveis a disposição do eleitor. Pensando em alternativas viáveis em uma dimensão mais quantitativa do que qualitativa, Sniderman e Levenduscky (2007) apontam que a restrição do número de alternativas disponíveis 
concorrendo em uma eleição auxiliaria a escolha eleitoral. Estudos mostram que a coerência nas escolhas pode vir a variar inversamente ao número de alternativas, uma vez que a restrição é um fator relevante para a consistência do sistema de crenças. Como sistemas multipartidários deteriam maior número de partidos efetivos, estariam, assim, relacionados a uma dificuldade no discernimento das alternativas disponíveis (ANDERSON, 2000). Uma vez que os discursos eleitorais tenderiam a estarem mais dispersos, o candidato situacionista estaria menos propenso a ser punido ou recompensado pelo seu desempenho na esfera econômica.

Para mensurar a clareza das alternativas disponíveis faz-se relevante mensurar o número de partidos efetivos, a partir da formula Lakso e Taagepera. A vantagem de usar esta fórmula, ao invés de apenas contabilizar os candidatos, é devido a sua capacidade de distinguir partidos que sejam de fato significativos daqueles com menor expressividade eleitoral.

Outro aspecto incorporado ao conceito de clareza de responsabilidade por Anderson (2000) seria em relação ao tamanho do partido do candidato situacionista. Tal variável vai ao encontro da ideia de clareza da responsabilidade, no entanto, discorda de Powell e Whitten (1993), ao ter em vista que enquanto a estrutura institucional tende a não mudar muito numa escala temporal, os resultados eleitorais e negociaçóes políticas alteram os agentes que compóem o ambiente político. Assim, faz-se relevante ver como esse fator, que pode vir a sofrer mudanças em decorrências das eleições, interage com as estruturas institucionais no processo de clareza de responsabilidade. Em sua análise, Anderson (2000), mensura o tamanho do partido situacionista a partir do número de cadeiras ocupadas na Câmara legislativa, bem como a ocupação em cargos ministeriais que compóem a base governamental. É relevante ressaltar que tais pressupostos teóricos têm em vista sistemas políticos estáveis, em que o eleitor entende minimamente a complexidade da formação parlamentar.

Ao ter como variável dependente o voto e como variável independente a avaliação econômica retrospectiva sociotrópica e egoísta, bem como variáveis de controle (religião, classe social e ideologia), Anderson (2000) conclui que o contexto político desempenha um relevante papel na relação entre voto no candidato situacionista e avaliação econômica. Ou seja, onde há níveis altos de clareza da responsabilidade, menor índice de partidos efetivos pleiteando uma vaga e maior inserção do partido situacionista na base de governo e no meio legislativo, o eleitor tenderá a punir ou recompensar mais o mandatário em decorrência de seu desempenho na esfera econômica. Em contrapartida, em países em que se têm 
impeditivos para uma clareza da responsabilidade, o mandatário, mesmo desempenhando de forma negativa uma gestão, não estaria tão exposto a perder votos como estaria caso o desenho institucional facilitasse o processo de compreensão da accountability (ANDERSON, 2000).

As instituiçóes se mostram, portanto, enquanto uma variável relevante. Mas para análise do contexto latino-americano é importante contemplar as variantes do regime presidencialista.

\section{A discussão neoinstitucionalista em países presidencialistas}

Uma vez compreendido o papel da economia na decisão eleitoral, bem como o papel do desenho institucional nesse campo de análise do voto econômico, estudos como os de Samuels (2004), Camargos (2006) e Correa (2014) evidenciam a relevância de atentar para as peculiaridades dos sistemas presidencialistas. Mainwaring e Shugart (2002) e Shugart e Carey (1992), defendem que é necessário ter em vista, ao analisar o presidencialismo, o contexto social, econômico e político em que se instaurou tal sistema político, bem como as variaçóes possíveis na medida em que a combinaçáo dessas variáveis gera distintos resultados. Assim, para além do conceito de clareza de responsabilidade, faz-se relevante o modelo proposto por Shugart e Carey (1992) para regimes presidencialistas.

Um sistema eficiente, segundo Shugart e Carey (1992), seria aquele relacionado com uma capacidade elevada de identificação e diferenciaçáo das informaçôes à disposição. Durante o processo eleitoral, tal discernimento dos programas políticos a disposiçáo do eleitor é de relevante importância para o processo avaliativo de governo e processamento da decisão eleitoral. Nesse sentido, sistemas eleitorais que enfocam em temáticas de caráter nacional, ao invés de aspectos paroquialistas, bem como, sistemas partidários com menor fragmentação, seriam considerados eficientes. Sistemas ineficientes, por sua vez, estariam relacionados à contemplação eleitoral da representatividade de diversos segmentos da sociedade. Averigua-se, portanto, um dilema entre eficiência e representatividade.

Como nos regimes presidencialistas há um processo eleitoral distinto para o executivo e legislativo, como também sobrevivência independente entre tais esferas de poder, não haveria, necessariamente, o impasse entre interesses provincianos (representação assegurada no legislativo) e um processo alto de identificação (eficiência assegurada no executivo). Poderia haver, destarte, um presidente eficiente, com pautas nacionais, e um legislativo representativo. No regime parlamentarista, por 
sua vez, não haveria a possibilidade de meio termo, ou seja, o sistema seria eficiente, tendo pautas nacionais, ou não. Em regimes presidencialistas, portanto, tal "trade-off" entre a representação de pautas particularistas e políticas nacionais seria ameno, em princípio.

Quando há um processo de nacionalização das pautas políticas na formação do legislativo em países presidencialistas, averígua-se uma tendência de isso ocorrer por conta de uma característica do sistema eleitoral. Quando o processo de eleição do legislativo se dá por lista fechada, onde os líderes partidários teriam controle sobre a ordenação de postulantes que serão eleitos conforme a fórmula eleitoral, tenderia a haver menor estimulo para estratégias que visassem a angariação de votos de modo individual. Em decorrência da dependência do resultado coletivo do partido nas eleiçóes, a figura ideológica e o programa político partidário ganham maior atençáo. Deste modo, evidencia-se que características do sistema eleitoral podem vir a impactar na configuração do sistema partidário (SHUGART e CAREY, 1992). Além desse aspecto atinente ao sistema eleitoral que se relaciona diretamente aos contornos partidários observáveis, o ciclo eleitoral é outra questão da mesma natureza. Em eleiçóes concomitantes, ou seja, quando as eleiçóes para executivo e legislativo ocorrem ao mesmo tempo, segundo Shugart e Carey (1992), o partido tende a focar em aspectos nacionais nas campanhas legislativas, quando comparado com aquelas eleiçôes que náo são concomitantes. $\mathrm{O}$ partido do presidente apresenta também maiores probabilidades de deter uma parcela significativa de assentos no parlamento. Posta esta caracterização partidária nacional, decorrente do sistema de lista fechada para eleição do legislativo e eleiçôes concomitantes, o processo de identificaçáo elevase e, com isso, maior será o grau de eficiência nos sistemas presidencialistas. O fato de o partido do governante ocupar uma parcela significativa de assentos parlamentares, quando o executivo e legislativo compactuam do ciclo eleitoral, também é um aspecto que auxilia no processo de identificaçáo, na medida em que auxiliaria no decorrer da gestão com a aprovação de pautas legislativas.

Em relação, especificamente, à forma de eleição do executivo, verifica-se que sistemas que têm seus presidentes eleitos por maioria simples (pluralidade) tendem a ter menor número de partidos efetivos em disputa quando comparado àqueles que têm seu processo de eleição majoritária com dois turnos. Isso decorre pelo fato de ser menos vantajoso coligar-se em um primeiro turno. Na medida em que maior grau de identificação está relacionado diretamente com eficiência, eleição por pluralidade, em um único turno, seria o arranjo institucional ideal para o alcance da eficiência. No que se refere ao sistema proporcional, Shugart e Carey (1992) apontam que, embora 
garanta a representatividade, é uma forma de eleição que tende a aumentar o número de partidos efetivos. Quando se alia a forma de eleição majoritária, como é o caso brasileiro, aumentaria a possibilidade de fragmentação partidária e, por sua vez, de ineficiência do regime.

Um modelo eficiente na configuração presidencialista seria aquele que apresenta um sistema partidário fortalecido nacionalmente, com uma liderança partidária forte e um executivo com restritos poderes presidenciais, eleito por maioria simples em eleições concomitantes. Esta combinação seria menos suscetível a crises e permitiria que partidos se voltem para pautas nacionais, sendo, deste modo, mais propícios a identificação e implementação de políticas nacionais. Quando um sistema legislativo é formado por relaçóes clientelistas, o poder de veto, que estaria embasado em políticas nacionais, ficaria enfraquecido. Assim, mesmo que o presidente detenha fortes poderes legislativos, ele precisa, também, de maiorias parlamentares para impor sua agenda política. A soberania legislativa está relacionada a um congresso majoritário. Ao manter um legislativo mais forte que os poderes legislativos do presidente, além de garantir a viabilidade como "policy-making body", para os autores, evita o risco de ter um legislativo marginalizado pelo presidente. Uma vez que este modelo assegura meios que auxiliam na maior identificação das alternativas à disposição, bem como, garantem a implantação de políticas de abrangência nacional que, por consequência, também auxiliarão na identificação, é dado como mais eficiente que o modelo em que teria menor "trade-off" entre representatividade e eficiência (legislativo representativo e executivo eficiente).

\section{Análise}

Ao ter por pressuposto teórico que há cenários com maior/menor clareza de responsabilidade, espera-se que tais variáveis intervenham na percepção que o eleitor terá do cenário econômico e social e no julgamento das responsabilidades do presidente em relação a esse desempenho, como aponta a Figura 1. Tal percepção, por sua vez, refletiria na avaliação que o presidente receberá. 
Figura 1 - Modelo neoinstitucional do voto econômico

\begin{tabular}{|c|}
\hline VARIÁVEIS \\
INSTITUCIONAIS \\
\hline
\end{tabular}

VARIÁVEIS ECONÔMICAS
- Avaliação sociotrópica retrospectiva
- Avaliação individual retrospectiva
- Crescimento Econômico
- Inflação
- Taxa de desemprego

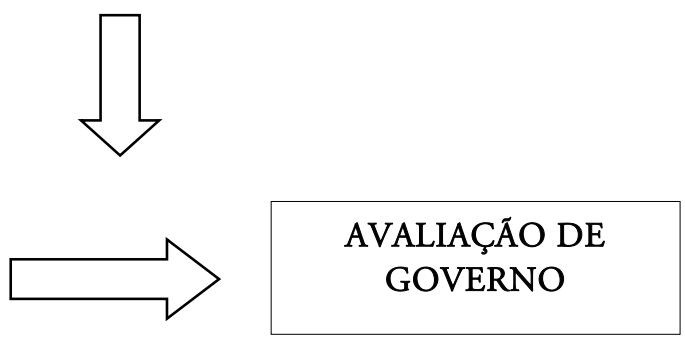

Fonte: Elaboração própria.

Enquanto variável dependente tem-se a avaliação de governo ${ }^{1}$ referente ao segundo ano de mandato ${ }^{2}$ de presidentes latino-americanos, entre 2008 e 2012, a partir da base de dados disponibilizados pelo Barômetro das Américas.

Com intuito de abranger as variáveis institucionais, teve-se em consideração três eixos: sistema partidário, sistema eleitoral e sistema político. No que se refere às variáveis que contemplariam o sistema partidário, foi considerado a fragmentação partidária, número de partidos efetivos no parlamento e porcentagem de cadeiras ocupadas pelo partido do presidente na Câmara dos Deputados. No que concerne às variáveis do sistema eleitoral, foi mensurado o modo de eleição do executivo e legislativo, bem como se havia segundo turno em relação ao executivo e o modo de

\footnotetext{
${ }^{1}$ Os presidentes contemplados na análise são: Argentina: Cristina Fernández de Kirchner; Bolívia: Juan Evo Morales; Brasil: Dilma Rousseff; Chile: Sebastián Piñera; Colômbia: Juan Manuel Santos Calderón; Costa Rica: Laura Chinchilla Miranda; El Salvador: Carlos Mauricio Funes Cartagena; Equador: Rafael Correia; Guatemala: Alvaro Colom; Honduras: Porfírio Lobo; México: Felipe Calderón; Nicarágua: Daniel Ortega Saavedra; Panamá: Ricardo Martinelli; Paraguai: Fernando Lugo; Peru: Ollanta Humala; República Dominicana Leonel Fernandez; República Dominicana: Leonel Fernandez; Uruguai: José Mujica; Venezuela: Hugo Chaves.

${ }^{2}$ Houve alguns casos que, por limitação de disponibilização dos bancos de dados, não foi possível seguir o proposto inicial de coletar informaçốes do segundo ano de gestão. A avaliação de governo reflete o primeiro ano de mandato no caso da Argentina, Nicarágua e Peru. Já os dados da Bolívia, El Salvador, Equador e Panamá se relacionam ao terceiro ano de mandato dos presidentes.
} 
lista (aberta ou fechada) nas eleiçôes legislativas. Por fim, no que se refere às variáveis do sistema político que se tornam pertinentes com o enfoque teórico que se pretende explorar posteriormente, tem-se os poderes constitucionais reativos (veto total e parcial) $)^{3}$.

O trabalho, portanto, tem as seguintes hipóteses:

$H 1-O$ voto econômico tenderá a se efetivar de maneira mais forte em cenários institucionais com mais transparência de responsabilidade:

H1.1 - Sistemas eleitorais caracterizados como sistemas majoritários ou sistemas proporcionais com lista fechada para eleiçóes do legislativo e um executivo eleito por maioria simples sem possibilidade de segundo turno, incidiráo positivamente na clareza de responsabilidade e eficiência. Assim, países que apresentem tais características tenderão a ter maior relação entre economia e avaliação do governo.

H1.2 - O sistema partidário, marcado por baixa fragmentação, menor número de partidos efetivos e maior porcentagem de cadeiras ocupadas pelo partido do presidente, são características relacionadas à maior clareza de responsabilidade e eficiência. Assim, onde houver tais características, maior será a relação entre economia e avaliaçáo do governo.

H1.3- Presidentes com fracos poderes reativos estäo relacionados a sistemas políticos eficientes. Quando o sistema político é eficiente, maior vinculação entre economia e avaliação do governo.

Para a realização das análises os bancos de dados serão divididos entre aqueles casos com maior e menor clareza de responsabilidade do fator que versa sobre sistema partidário para, na sequência, fazermos um teste de correlaçáo entre as variáveis independentes econômicas - dos níveis individual e agregado - e a variável dependente. O objetivo é constatar se há mais frequente e alta correlaçáo entre as variáveis em teste no caso de países imersos em realidade de alto fator do sistema partidário, como - a partir de nossa hipótese 1.1 - se pode esperar. $\mathrm{O}$ passo seguinte é repetir o procedimento, dividindo o banco de dados de acordo com o nível de clareza de responsabilidade dos fatores sistema eleitoral e sistema de governo a fim de testar as demais hipóteses, 1.2 e 1.3 .

Apesar de o modo mais adequado para realizar tal análise seria o modelo multinível, isto não foi possível na medida em que para testar a hipótese da clareza de responsabilidade seria necessário dividir a amostra total entre países com maior e

3 A partir da análise fatorial, foram desconsideradas as seguintes variáveis: número de partidos efetivos do Executivo; Magnitude média dos distritos da Câmara dos Deputados e poder de decreto. 
menor clareza e, assim, cada sub-amostra contaria então com apenas oito casos, o que para uma análise multinível é muito pouco.

Fator sistema partidário: As avaliaçôes retrospectiva e prospectiva estão significativamente e positivamente correlacionadas com a avaliação do mandatário (sig 0,000 ) nos dois subgrupos de acordo com a teoria do voto econômico. Contudo, a hipótese da clareza de responsabilidade náo fica confirmada, pois tanto em contexto de menor quanto de maior clareza de responsabilidade do sistema partidário encontra-se correlaçóes válidas, positivas e com forças muito parecidas, não havendo qualquer distinção do padrão de decisão do voto econômico nos dois cenários.

As variáveis macroeconômicas também se mostraram significativamente e positivamente correlacionadas com a avaliação do mandatário (sig 0,000) nos dois subgrupos. Contudo, o sentido do impacto é precisamente o oposto do que se poderia esperar em um contexto de alta clareza de responsabilidade: correlaçáo positiva com a avaliação do desempenho do mandatário no caso de inflação e de desemprego e correlação negativa no caso de crescimento econômico. No subgrupo de países com baixa clareza de responsabilidade, repete-se a correlaçáo positiva com a avaliação do desempenho do mandatário no caso de inflação e desemprego.

Neste sentido, os achados se aproximam do que Cheibub e Prezworski (1997) encontraram em seu estudo, que a clareza de responsabilidade náo necessariamente interfere no sentido de promover o padrão de comportamento do voto econômico e, consequentemente, no tempo de duração dos mandatos.

Fator sistema eleitoral: Assim como ocorre quando há em consideração o fator partidário, as avaliaçóes retrospectiva e prospectiva estáo significativamente e positivamente correlacionadas com a avaliação do mandatário (sig 0,000). Mas a hipótese da clareza de responsabilidade não é confirmada mais uma vez, na medida em que há sutis diferenças nos coeficientes de correlação.

No que se referem às variáveis macroeconômicas, estas também se mostraram significativamente e positivamente correlacionadas com a avaliação do mandatário em cenários maior e menor clareza de responsabilidade. Excetua-se a inflaçáo, que está negativamente correlacionada em países com maior clareza de responsabilidade. Inflação se mostra no sentido esperado nesses países, embora a correlação seja baixa (0.077). Taxa de crescimento também se apresenta no sentido esperado em ambos os subgrupos, embora não confirme a hipótese de maior correlação em países com maior clareza de responsabilidade. Em relação à taxa de desemprego, contudo, o sentido do impacto é precisamente o oposto ao que se poderia esperar em países com maior e menor clareza: correlaçáo positiva com a avaliaçáo do desempenho do mandatário. 
Fator dos poderes reativos dos presidentes: Por fim, analisando a diferença da clareza de responsabilidade, tendo em vista os poderes reativos dos presidentes, é possível observar que se segue a tendência anteriormente exposta. Ambas as avaliaçóes econômicas subjetivas estão correlacionadas positivamente com a avaliação do governo. Entretanto a hipótese H1.3 não é corroborada na medida em que as diferenças entre os coeficientes de correlaçóes são sutis.

Em relação às variáveis que versam sobre índices econômicos nacionais, taxa de desemprego não apresenta uma relação estatisticamente significativa em todos os casos. Inflação, por sua vez, está negativamente correlacionada com a avaliação do governo apenas em países com maior clareza de responsabilidade. Em países com menor clareza não há uma relação estatisticamente significativa. Taxa de desemprego, assim como ocorre nos fatores anteriormente expostos, está em sentido oposto ao esperado.

Tabela 1 - Quadro de correlaçóes de variáveis econômicas independentes por variável dependente em contextos institucionais distintos marcados por menor ou maior clareza de responsabilidade

\begin{tabular}{c|c|c|c|c|c|c}
\hline & \multicolumn{2}{|c|}{ Fator partidário } & \multicolumn{2}{c|}{ Fator eleitoral } & \multicolumn{2}{c}{$\begin{array}{c}\text { Fator dos poderes reativos } \\
\text { dos presidentes }\end{array}$} \\
\hline Variáveis & $\begin{array}{c}\text { Maior } \\
\text { clareza }\end{array}$ & $\begin{array}{c}\text { Menor } \\
\text { Clareza }\end{array}$ & $\begin{array}{c}\text { Maior } \\
\text { clareza }\end{array}$ & $\begin{array}{c}\text { Menor } \\
\text { Clareza }\end{array}$ & $\begin{array}{c}\text { Maior } \\
\text { clareza }\end{array}$ & Menor Clareza \\
\hline $\begin{array}{c}\text { Avaliaçáo } \\
\text { retrospectiva } \\
\text { individual }\end{array}$ & $0.204^{* * *}$ & $0.227^{* * *}$ & $0.220^{* * *}$ & $0.212^{* * *}$ & $0.222^{* * *}$ & $0.209^{* * *}$ \\
\hline $\begin{array}{c}\text { Avaliaçáo } \\
\text { retrospectiva } \\
\text { sociotrópica }\end{array}$ & $0.302^{* * *}$ & $0.332^{* * *}$ & $0.325^{* * *}$ & $0.307^{* * *}$ & $0.336^{* * *}$ & $0.305^{* * *}$ \\
\hline Inflaçáo & $0.073^{* * *}$ & $0.212^{* * *}$ & $-0.077^{* * *}$ & $0.223^{* * *}$ & $-0.026^{*}$ & 0.005 \\
\hline Desemprego & $0.206^{* * *}$ & $0.039^{* * *}$ & $0.120^{* * *}$ & $0.031^{* * *}$ & $0.234^{* * *}$ & $0.021^{*}$ \\
\hline Taxa de crescimento & $-0.37^{* * *}$ & $0.154^{* * *}$ & $0.019^{*}$ & $0.125^{* * *}$ & 0.016 & 0.013 \\
\hline
\end{tabular}

*** $\operatorname{sig} 0,000$

Fonte: Barômetro das Américas (2008-2012) e Banco de dados da autora

Assim, é possível observar a saliência do voto econômico. Avaliaçáo subjetiva da economia, seja esta retrospectiva sociotrópica ou individual, apresenta fortes correlaçóes. As variáveis de nível macroestrutural, tais como inflação, taxa de desemprego e taxa de crescimento, de todo modo, apesar de se mostrarem estatisticamente significativas, são incoerentes ou o coeficiente de correlação é baixo. 
56 | Jaqueline da Silva Borges

$\mathrm{Na}$ sequência foram realizadas regressóes tendo em consideração apenas as variáveis econômicas subjetivas.

A Tabela 2 traz informaçóes sobre o fator partidário. Como era previsto, a relação entre avaliação da economia, sendo esta sociotrópica ou individual, e avaliação dada ao presidente latino-americano é estatisticamente significativa: quanto melhor for a avaliaçáo da economia, maior a probabilidade de que o presidente receba uma avaliação positiva. Além disso, a partir dos coeficientes, é possível observar que tal relação é relativamente maior em países com maior clareza de responsabilidade. Dito de outro modo, em países que apresentam menor número de partidos efetivos, menor fragmentação partidária e o partido situacionista ocupe maior porcentagem de cadeiras na Câmara dos Deputados, será possível observar maior relação entre economia e avaliação do governo. Importante salientar também que a avaliação sociotrópica é uma variável com maior peso explicativo, tanto em países com maior ou menor clareza de responsabilidade, quando comparado à avaliação da economia individual. Isto pode estar relacionado com a abrangência de atuação do cargo em que se está em discussão (executivo nacional). 
Tabela 2 - Variáveis econômicas de nível individual (Partidário)

\begin{tabular}{|c|c|c|c|c|c|}
\hline \multicolumn{6}{|c|}{ Maior clareza de responsabilidade } \\
\hline Fixed Effect & Coefficient & $\begin{array}{r}\text { Standard } \\
\text { error }\end{array}$ & $t$-ratio & $\begin{array}{r}\text { Approx. } \\
\text { d.f. }\end{array}$ & $p$-value \\
\hline \multicolumn{6}{|l|}{ For INTRCPT1, $\beta_{0}$} \\
\hline INTRCPT2, $\gamma_{o o}$ & 2.090473 & 0.192338 & 10.869 & 7 & $<0.001$ \\
\hline \multicolumn{6}{|l|}{ For SOCT1 slope, $\beta_{1}$} \\
\hline INTRCPT $2, \gamma_{10}$ & 0.328413 & 0.056642 & 5.798 & 7 & $<0.001$ \\
\hline \multicolumn{6}{|l|}{ For IDI01 slope, $\beta_{2}$} \\
\hline INTRCPT2, $\gamma_{20}$ & 0.093628 & 0.021176 & 4.421 & 7 & 0.003 \\
\hline \multicolumn{6}{|c|}{ Menor clareza de responsabilidade } \\
\hline Fixed Effect & Coefficient & $\begin{array}{r}\text { Standard } \\
\text { error }\end{array}$ & $t$-ratio & $\begin{array}{r}\text { Approx. } \\
\text { d.f. }\end{array}$ & $p$-value \\
\hline \multicolumn{6}{|l|}{ For INTRCPT $1, \beta_{0}$} \\
\hline INTRCPT2, $\gamma_{o o}$ & 2.329244 & 0.149262 & 15.605 & 7 & $<0.001$ \\
\hline \multicolumn{6}{|l|}{ For SOCT1 slope, $\beta_{1}$} \\
\hline INTRCPT2, $\gamma_{10}$ & 0.242890 & 0.024732 & 9.821 & 7 & $<0.001$ \\
\hline \multicolumn{6}{|l|}{ For IDI01 slope, $\beta_{2}$} \\
\hline INTRCPT2, $\gamma_{20}$ & 0.079218 & 0.012921 & 6.131 & 7 & $<0.001$ \\
\hline
\end{tabular}

SOCT1 = avaliação econômica sociotrópica retrospectiva; IDI01 = avaliação econômica individual retrospectiva.

Fonte: Banco de dados da autora.

A Tabela 3, que versa sobre variáveis econômicas no nível individual do fator eleitoral, aponta uma tendência contraria a encontrada anteriormente. Com relaçóes estatisticamente significativas, a avaliação sociotrópica é mais forte em países com menor clareza de responsabilidade. Já em relação à avaliação econômica individual a expectativa é suprida. Ou seja, é possível observar que o coeficiente é maior em países com maior clareza de responsabilidade. 
Tabela 3 - Variáveis econômicas de nível individual (Eleitoral)

\begin{tabular}{|c|c|c|c|c|c|}
\hline \multicolumn{6}{|c|}{ Maior clareza de responsabilidade } \\
\hline Fixed Effect & Coefficient & $\begin{array}{r}\text { Standard } \\
\text { error }\end{array}$ & $t$-ratio & $\begin{array}{r}\text { Approx. } \\
\text { d.f. }\end{array}$ & $p$-value \\
\hline \multicolumn{6}{|l|}{ For INTRCPT1, $\beta_{0}$} \\
\hline INTRCPT2, $\gamma_{o o}$ & 2.120581 & 0.165880 & 12.784 & 6 & $<0.001$ \\
\hline \multicolumn{6}{|l|}{ For SOCT1 slope, $\beta_{1}$} \\
\hline INTRCPT $2, \gamma_{10}$ & 0.261186 & 0.035334 & 7.392 & 6 & $<0.001$ \\
\hline \multicolumn{6}{|l|}{ For IDI01 slope, $\beta_{2}$} \\
\hline INTRCPT $2, \gamma_{20}$ & 0.105216 & 0.022572 & 4.661 & 6 & 0.003 \\
\hline \multicolumn{6}{|c|}{ Menor clareza de responsabilidade } \\
\hline Fixed Effect & Coefficient & $\begin{array}{r}\text { Standard } \\
\text { error }\end{array}$ & $t$-ratio & $\begin{array}{r}\text { Approx. } \\
\text { d.f. }\end{array}$ & $p$-value \\
\hline \multicolumn{6}{|l|}{ For INTRCPT1, $\beta_{0}$} \\
\hline INTRCPT2, $\gamma_{o o}$ & 2.344825 & 0.134043 & 17.493 & 8 & $<0.001$ \\
\hline \multicolumn{6}{|l|}{ For SOCT1 slope, $\beta_{1}$} \\
\hline INTRCPT2, $\gamma_{10}$ & 0.274112 & 0.028808 & 9.515 & 8 & $<0.001$ \\
\hline \multicolumn{6}{|l|}{ For IDI01 slope, $\beta_{2}$} \\
\hline INTRCPT2, $\gamma_{20}$ & 0.076128 & 0.010701 & 7.114 & 8 & $<0.001$ \\
\hline
\end{tabular}

SOCT1 = avaliação econômica sociotrópica retrospectiva; IDI01 = avaliação econômica individual retrospectiva.

Fonte: Banco de dados da autora.

Os achados contradizem o que diz a literatura a respeito da clareza de responsabilidade, ao menos no que se refere à avaliação retrospectiva sociotrópica. $\mathrm{Ou}$ seja, variáveis eleitorais relacionadas a cenários com maior clareza de responsabilidade não necessariamente refletem em uma maior relaçáo entre a economia e avaliação do governo. Ao menos não diretamente, na medida em que é possível que regras eleitorais possam vir a impactar na configuração do sistema partidário que, como já mostrado anteriormente, explicariam as diferenças entre os países na relação entre economia e avaliação do governo.

A Tabela 04, sobre poderes reativos dos presidentes, aponta que tanto a variável econômica individual quanto a variável econômica sociotrópica apresentam um coeficiente mais elevado em países com menor clareza de responsabilidade. A hipótese sobre clareza de responsabilidade, portanto, não é confirmada. Ou seja, um dos aspectos que caracteriza um sistema eficiente não leva a maior relação entre avaliação subjetiva da economia e avaliação do governo. 
Tabela 4 - Variáveis econômicas de nível individual (Poderes reativos dos presidentes)

\begin{tabular}{|c|c|c|c|c|c|}
\hline \multicolumn{6}{|c|}{ Maior clareza de responsabilidade } \\
\hline Fixed Effect & Coefficient & $\begin{array}{r}\text { Standard } \\
\text { error }\end{array}$ & $t$-ratio & $\begin{array}{r}\text { Approx. } \\
\text { d.f. }\end{array}$ & $p$-value \\
\hline \multicolumn{6}{|l|}{ For INTRCPT1, $\beta_{0}$} \\
\hline INTRCPT2, $\gamma_{00}$ & 2.430347 & 0.154656 & 15.715 & 6 & $<0.001$ \\
\hline \multicolumn{6}{|l|}{ For SOCT1 slope, $\beta_{1}$} \\
\hline INTRCPT2, $\gamma_{10}$ & 0.243051 & 0.036162 & 6.721 & 6 & $<0.001$ \\
\hline \multicolumn{6}{|l|}{ For IDI01 slope, $\beta_{2}$} \\
\hline INTRCPT $2, \gamma_{20}$ & 0.088149 & 0.019582 & 4.502 & 6 & 0.004 \\
\hline \multicolumn{6}{|c|}{ Menor clareza de responsabilidade } \\
\hline Fixed Effect & Coefficient & $\begin{array}{r}\text { Standard } \\
\text { error }\end{array}$ & $t$-ratio & $\begin{array}{r}\text { Approx. } \\
\text { d.f. }\end{array}$ & $p$-value \\
\hline \multicolumn{6}{|l|}{ For INTRCPT $1, \beta_{0}$} \\
\hline INTRCPT $2, \gamma_{00}$ & 2.104282 & 0.130050 & 16.181 & 8 & $<0.001$ \\
\hline \multicolumn{6}{|l|}{ For SOCT1 slope, $\beta_{1}$} \\
\hline INTRCPT2, $\gamma_{10}$ & 0.287727 & 0.026131 & 11.011 & 8 & $<0.001$ \\
\hline \multicolumn{6}{|l|}{ For IDI01 slope, $\beta_{2}$} \\
\hline INTRCPT $2, \gamma_{20}$ & 0.089694 & 0.016959 & 5.289 & 8 & $<0.001$ \\
\hline
\end{tabular}

SOCT1 = avaliação econômica sociotrópica retrospectiva; IDI01 = avaliação econômica individual retrospectiva.

Fonte: Banco de dados da autora.

Em suma, tendo em vista o período em estudo, é possível confirmar a tese do voto econômico na América Latina. Ao menos as variáveis econômicas de nível individual explicam a avaliação do governo. E mais, variáveis institucionais, tais como as atinentes ao sistema partidário e eleitoral (ao menos na relação entre avaliação retrospectiva individual e avaliação do governo), auxiliam a compreender a variação em tal relação. A linha teórica que aponta a pertinência explicativa de variáveis institucionais no comportamento eleitoral, assim, é, em alguma medida, endossada.

Sistemas presidencialistas apresentam relevantes variaçóes institucionais que, para além de assegurar a governabilidade, podem auxiliar ou prejudicar o processo de clareza de responsabilidade e eficiência do sistema político. Portanto, estudar tal sistema político e suas particularidades, bem como a forma como esse desenho institucional reflete no comportamento eleitoral latino-americano, é fecundo para consolidação democrática. 


\section{Considerações finais}

Com o levantamento bibliográfico acerca do voto econômico, é possível observar que apesar de variaçóes quanto ao modelo de análise e variáveis empregadas, a economia ainda apresenta relevante peso explicativo no comportamento eleitoral. Avançando nessa discussão do voto econômico, há autores que apontam a necessidade de ater-se ao contexto institucional ao qual o eleitor está inserido. Com uma gama elevada de variáveis atinentes ao sistema político, eleitoral e partidário, os estudos transnacionais apontam a riqueza explicativa de tais variáveis.

Partindo deste cenário, o presente trabalho teve por intuito analisar a avaliação de governos latino-americanos entre 2008 e 2012. Para tanto, teve por base teórica os conceitos de clareza de responsabilidade e sistema eficiente. Trazendo esta discussão institucionalista para um estudo transnacional da regiáo latino-americana, o trabalho também busca amenizar uma lacuna presente na literatura quanto à carência de pesquisas que possuem como variável dependente a avaliação de governo.

Ao recorrer às correlaçôes, por limitaçôes metodológicas, para analisar a avaliaçáo de governo de presidentes latino-americanos, tendo em vista aspectos institucionais, pouco pode ser inferido. Ou seja, as diferenças nos coeficientes de correlaçáo se mostram sutis ou inconsistentes com o esperado.

Ao descartar as variáveis econômicas objetivas e aplicando uma regressão linear com variáveis subjetivas, é possível observar o poder explicativo, ainda que sutil, de variáveis institucionais, tais como as atinentes ao sistema partidário e eleitoral (ao menos na relação entre avaliaçáo retrospectiva individual e avaliação do governo). Não são todas as variáveis institucionais que mostram poder explicativo na relação entre avaliação econômica e avaliação do governo, mas, ainda assim, não se pode desconsiderá-las em sua totalidade.

O presente trabalho reforçou também as nuances atinentes ao regime presidencialista, evidenciando a riqueza exploratória que há, dada as variaçóes nesse arranjo institucional. Haveria contornos específicos que assegurariam a clareza de responsabilidade, bem como, a eficiência. Além disso, apontou-se a necessidade de cautela quanto a generalizaçóes de uma possível insustentabilidade de tal regime para a consolidação democrática.

Estudar comportamento eleitoral pelo viés institucionalista é fecundo e pode vir a enriquecer o debate contemporâneo na Ciência Política. Muitas são as variáveis passíveis a serem exploradas, bem como, o recorte temporal. É necessário que o eleitor seja contextualizado e seja levado em consideração o cenário institucional, social e econômico em que o mesmo realiza suas escolhas. Além disso, tal perspectiva 
institucionalista levanta discussóes produtivas acerca de modos de otimização do desempenho institucional.

Jaqueline da Silva Borges é Mestre em Ciência Politica, pela Universidade Federal do Paraná. E-mail: jaquelineborges06@gmail.com.

\section{Referências}

ANDERSON, Christopher. Economic voting and political context a comparative perspective. Electoral Studies, n. 19, 2000. p 151-170.

ANDERSON, Christopher J. The Interaction of Structures and Voter Behavior. In: DALTON, Russell J.; KLINGEMANN; Hans-Dieter (org.). Oxford Handbook of Political Behavior. New York: Oxford University Press, 2007

Barômetro das Américas. Latin American Public Opinion Project. Disponível em <http://www.americasbarometer.org/>.

BECK, Nathaniel. Parties, Administrations, and American Macroeconomic Outcomes. American Political Science Review, v. 76, 1982. p. 83-94.

BELLUCCI, Paolo. The Effect of Aggregate Economic Conditions on the Political Preferences of the Italian Electorate, 1953-1979. European Journal of Political Research, v. 12, 1984. p. 387-412.

BENTON, Allyson. Dissatisfied democrats or retrospective voters? Economic hardship, political institutions and voting behavior in Latin America. División de Estudios Políticos, n. 153, 2003. p. 387-412.

CAMARGOS, Malco Braga Economia e eleiçóes na América Latina: refinando a teoria do Voto Econômico. In: 30 Encontro Anual da ANPOCS, 2006.

CHEIBUB, José Antonio; PRZEWORSKI, Adam. Democracia, Eleições e responsabilidade política. Revista Brasileira de Ciências Sociais. v. 12, n. 35, 1997.

CORREAA. Diego Sanches. O voto econômico na América Latina. In: Anais $9^{\circ}$ Encontro da Associação Brasileira de Ciência Politica (ABCP), Brasília- DF, 2014.

DALTON, Russell J.; ANDERSON, Christopher J. (org). Citizens, Context and Choice: How Context Shapes Citizens' Electoral Choices Oxford: Oxford University Press, 2011.

EULAU, Heinz; LEWIS-BECK, Michael S. Economic Conditions and Electoral Outcomes. New York: Agathon. 1985.

FRANZ, Gerhard. Economic Aspirations, Well- Being, and Political Support in Recession and Boom Periods: The Case of West Germany. European Journal of Political Research, v. 14, 1986. p. 97-112.

HIBBS, Douglas A., Jr; FASSBENDER, Heino. Contemporary Political Economy. Amsterdam: NorthHolland. 1981. 
LEWIS-BECK, Michael S. Economicsa nd Elections: The Major Western Democracies. Ann Arbor: University of Michigan Press. 1988.

LEWIS-BECK, MICHAEL S. A.; MARTINI, Nicholar; KIEWIET, D. Roderick. The Nature of Economic Percepcion on mass publics. Electoral Studies, n. 32, 2013. p. 524-528.

LEWIS-BECK, Michael; STEGMAIER, Mary. Economic Determinants of Electoral Outcomes. Annual Review of Political Science. v. 3, 2000. p. 183-219.

LEWIS-BECK, Michael; STEGMAIER, Mary. The Economic Vote in transitional democracies. Journal of Elections, Public Opinion \& Parties, v. 18, n. 3, 2008. p. 303-323.

LEWIS-BECK, Michael; RATTO, Maria Celeste. Economic Voting in Latin America: a general model. Electoral Studies, n. 32, 2013. p. 489-493.

MAINWARING, Scott; SHUGART, Matthew. Presidencialismo y democracia en América Latina: revisión de los términos del debate. In: MAINWARING, Scott; SHUGART, Matthew (org.). Presidencialismo y democracia en América Latina. Buenos Aires: Padiós Latinoamericana. 2002.

POWELL, Bingham; WHITTEN, Guy. A cross-national analysis of economic voting: taking account of the political context. American Journal of Political Science. v. 37, n. 2, 1993. p. 391-414.

REMMER, Karen. The political impact of economic crisis in Latin America in the 1980s. American Political Science Review, n. 85, 1991. p. 777-800.

SAMUELS, David. Presidentialism and Accountability for Economy in Comparative Perspective. American Political Science Review, v. 98, n. 3, 2004. p. 425-436.

SHUGART, Matthew; CAREY, John. Presidents and Assemblies. Constitutional Design and Electoral Dynamics. Cambridge, Cambridge University Press. 1992

SINGER, Matthew. Economic Voting in an Era of (Non) Crisis: The Changing Electoral Agenda in Latin America 1982-2010. Comparative Politics, v. 45, n. 2, 2013. p. 169-185.

SNIDERMAN, Paul M.; LEVENDUSKY, Matthew S. An institutional theory of political choice. In: DALTON, Russell J.; KLINGEMANN, Hans-Dieter (org.). Oxford Handbook of Political Behavior. New York: Oxford University Press, 2007.

TUFTE, Edward R. Political Control of the Economy.Princeton: Princeton University Press. U.S. House. Committee on Foreign Affairs. 1986. Global Debt Crisis. 99th Cong., 2d sess. 1978.

VEIGA. Luciana Fernandes. Economic Voting an Age of Growth and Poverty Reduction: Electoral Response in Latin America (1995-2010). CSD Working Papers. Irvine, CA: Center for the Study of Democracy. 2013.

VISSER, Wessel; WIJNHOVEN, Rien. Politics Do Matter, but Does Unemployment?. European Journal of Political Research, v. 18, 1990. p. 71-96.

WEYLAND, Kurt. Peasants or Bankers in Venezuela? Presidential Popularity and Economic Reform Approval, 1989-1993. Political Research Quarterly, v. 51, n. 2, 1998. p. 341-362.

WEYLAND, Kurt. A Paradox of Success? Determinants of political support for President Fujimori. International Studies Quarterly, n. 44, 2000. p. 481-502.

Texto recebido em 25 de outubro de 2016. Aprovado em 07 de dezembro de 2016. 